\title{
FOOT STEERED TRICYCLE
}

\author{
Samip Mehta, Deven Godhani, Nauman Vadnagarwala, Chirag Shivdas \\ Mechanical Engineering Department, L.D College of Engineering, Ahmedabad, India
}

\begin{abstract}
Being handicapped cycle dependent may cause limitations in functioning, i.e. impede functions of daily living and/or participation. To improve ambulation, the Foot Steered user combination can be optimized at three levels. On the level of the user one can optimize physical capacity and technique by training. The second level focuses on the Foot steered tricycle user interface, i.e. the interaction between the human system and the geometry of both the seating orientation and steering mechanism, aiming for a higher efficiency. This operation gives us a better ratio of internal power from the user to the external power required for drive. Finally, at the level of the Tricycle the focus lies on minimizing power loss of the Tricycle-User by reducing frictional forces and optimizing the vehicle mechanics. To advance handicapped cycle design, better insight in the working mechanisms of our biological system in combination with a mechanical extension, such as the handicapped cycle is necessary.
\end{abstract}

Key words: Foot, steering, tricycle.

Cite this Article: Samip Mehta, Deven Godhani, Nauman Vadnagarwala, Chirag Shivdas, Foot Steered Tricycle. International Journal of Design and Manufacturing Technology 8(1), 2017, pp. 13-29. https://iaeme.com/Home/issue/IJDMT?Volume=8\&Issue=1

\section{INTRODUCTION}

\subsection{Brief History of Tricycle}

The first tricycle was built in 1680 for a German paraplegic named Stephan Farffler, who lived near Nuremburg. He was a watch-maker and the tricycle had gears and hand cranks.

Two Frenchmen, named Blanchard and Maguier invented a tricycle in 1789, which prompted the Journal de Paris to coin the words 'bicycle' and 'tricycle' and publish them on July 27th to differentiate between the two types of machines. Denis Johnson patented a tricycle in England in 1818, and a threewheeled swift walker was introduced in 1819.

On November 18, 1876, James Starley introduced the Coventry Lever Tricycle, a side-driven twotrack, lever-driven machine, and that started the tricycling craze in Great Britain. It had two small wheels on the right side, that both steered simultaneously. A large drive wheel was on the left side. In 1877, he introduced the Coventry Rotary, one of the first rotary chain drive tricycles.

In 1879, twenty types of tricycles and multi-wheel cycles were produced in Coventry, England, and by 1884, there were over 120 different models produced by 20 manufacturers. Tricycles were used especially by those who could not ride high wheelers, such as women who were confined in the long dresses of the day, and short or unathletic men. 


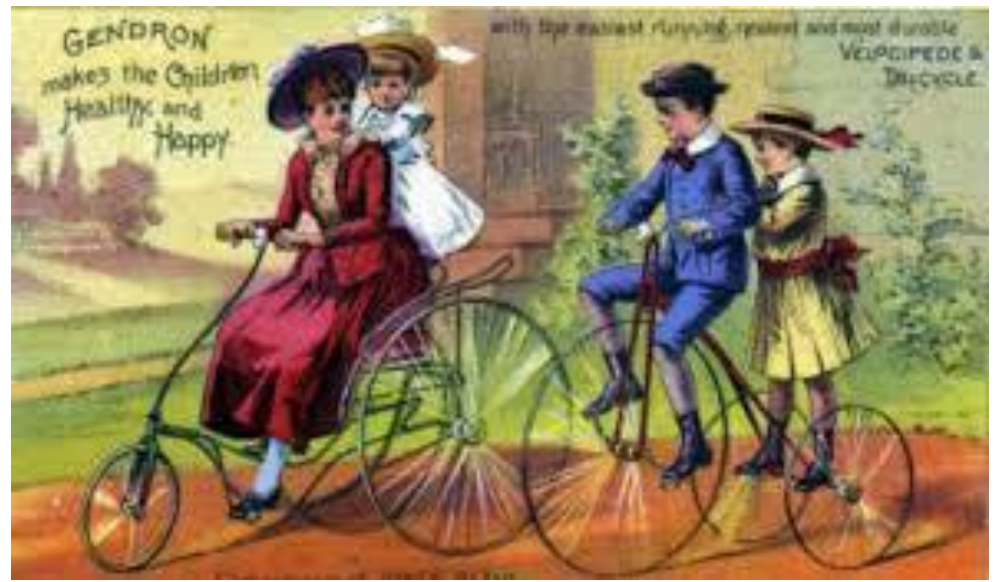

Figure 1

From 1881 to 1886 in Great Britain, more tricycles were built than bicycles, but this was primarily a class phenomenon, since tricycles were more expensive, perceived as more genteel, and the upper classes had the disposable income to buy them for the women in the family. As a result, tricycling remained popular in Great Britain long after riders turned away from them elsewhere. They even had regular racing.

By the 1990s, that was no longer true, and many British manufacturers stopped making them. In the United States, tricycles are used primarily by older persons for recreation, shopping, and exercise. In Asia and Africa, tricycles are used primarily for commercial transportation.

The tricycles produced from 1876 to 1884, of which Starley's Coventry Rotary is the most famous example, are considered first generation tricycles, and showed a wide variety of inventiveness as the best design was sought.

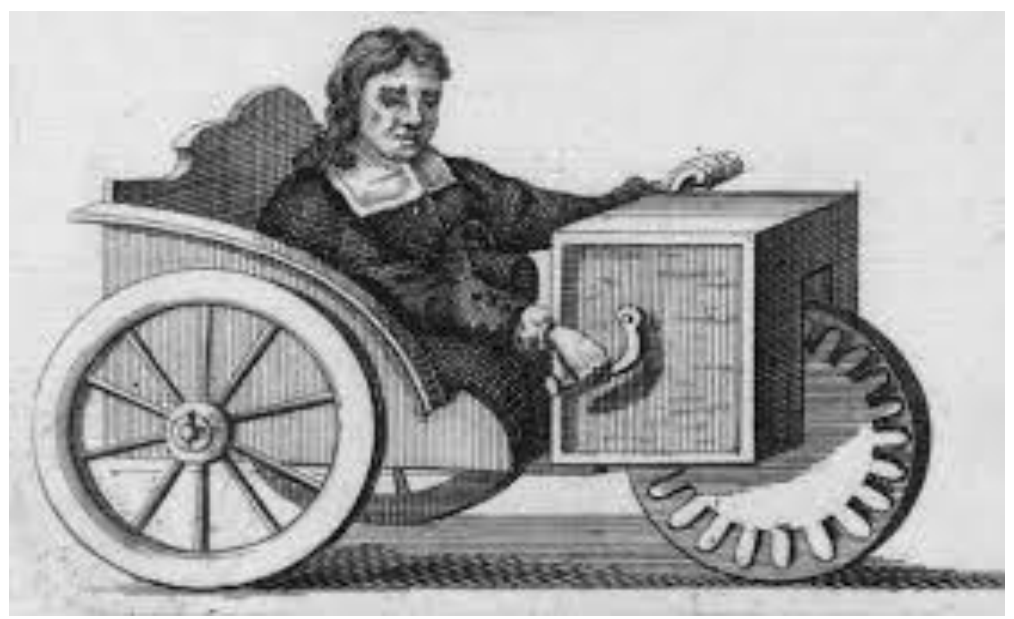

Figure 2

By 1885, the second generation of tricycles had appeared. The Humber Cripper, named for professional racer Robert Cripps, was typical. It had the modern pattern of two rear wheels with a front wheel bisecting their track. 


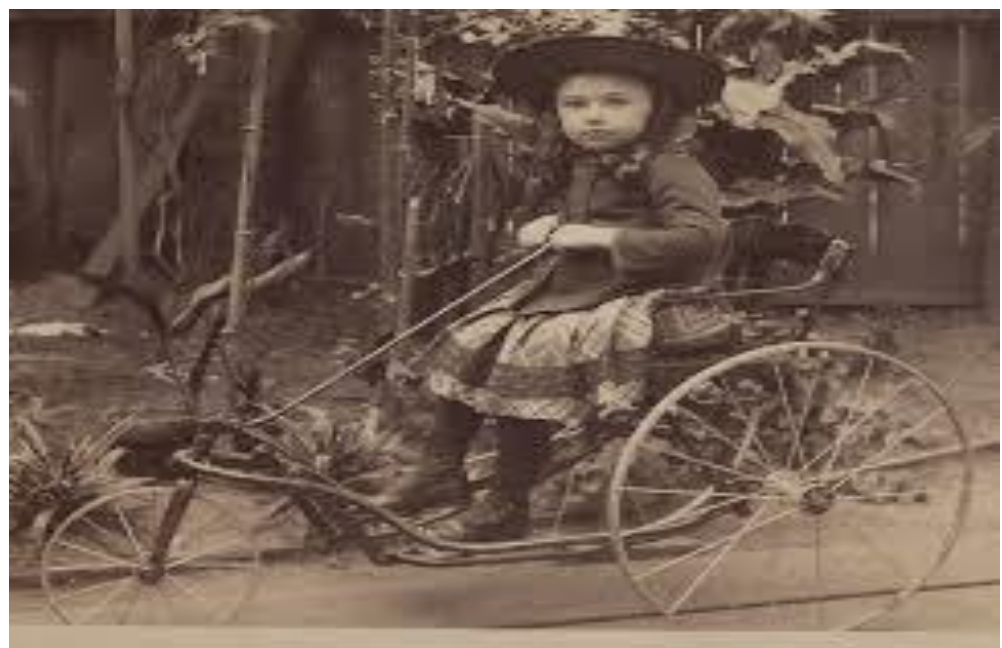

Figure 3

The third generation of tricycles is like todays, and the 1892 Starley Psycho was one of the first. All of its wheels were of equal size, in this case, 28 inches. By 1900 however, the pneumatic tired safety bicycle took away most of the tricycle business since it provided an adequate amount of stability for most riders.

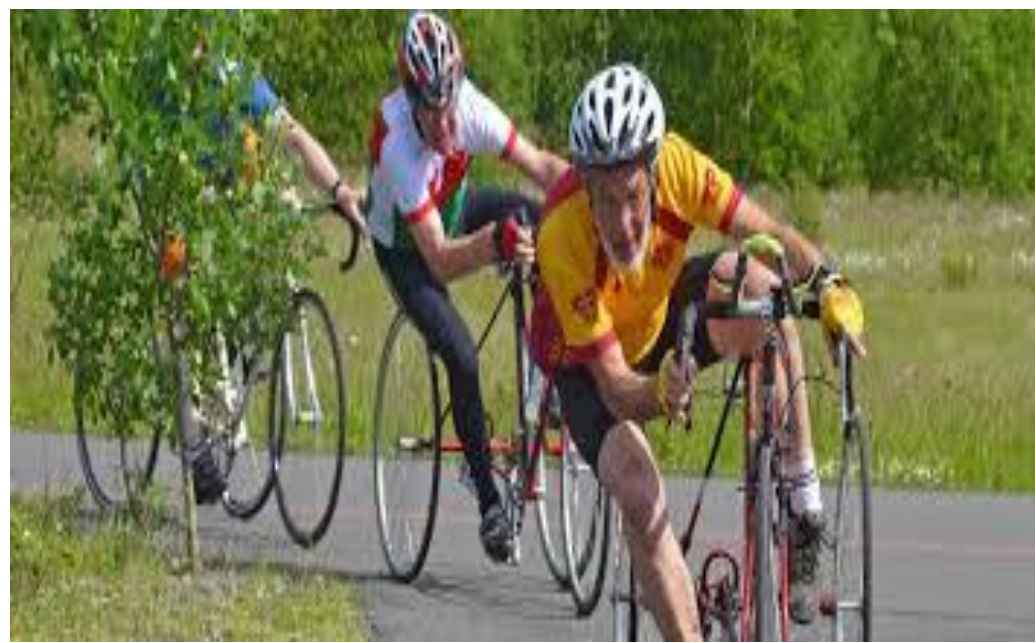

Figure 4

\section{PROJECT DEFINITION}

Designing of a Steering mechanism that can be achieved using foot. (Considering the people with upper body disability.)

\section{MOVEMENT DISABILITY}

"Movement disability" means disability of the bones, joints muscles leading to substantial restriction of the movement of the limbs or any form of cerebral palsy.

A Person, who lacks limbs or is unable to use limbs normally, will be considered having movement disability.

Person classified as Movement Disabled:

- Paralytic persons

- Those who crawl

- Those who are able to walk with the help of aid

- Have acute and permanent problems of joints/muscles 
- Have stiffness or tightness in movement or have loose, involuntary movements or tremors of the body or have fragile bones

- Have difficulty balancing and coordinating body movement

- Have loss of sensation in body due to paralysis, Leprosy etc.

- Have deformity of body like hunch back or are dwarf.

Movement Disability: 54,36,604 (33,07,374 Males + 20,66,230 Females)

$20.2 \%$ of Total Disabled People are having movement disability in India.

(According to Census 2011 and NSSO 2012 Data)

Proportion of Disabled Population by Residence

India : 2001-11

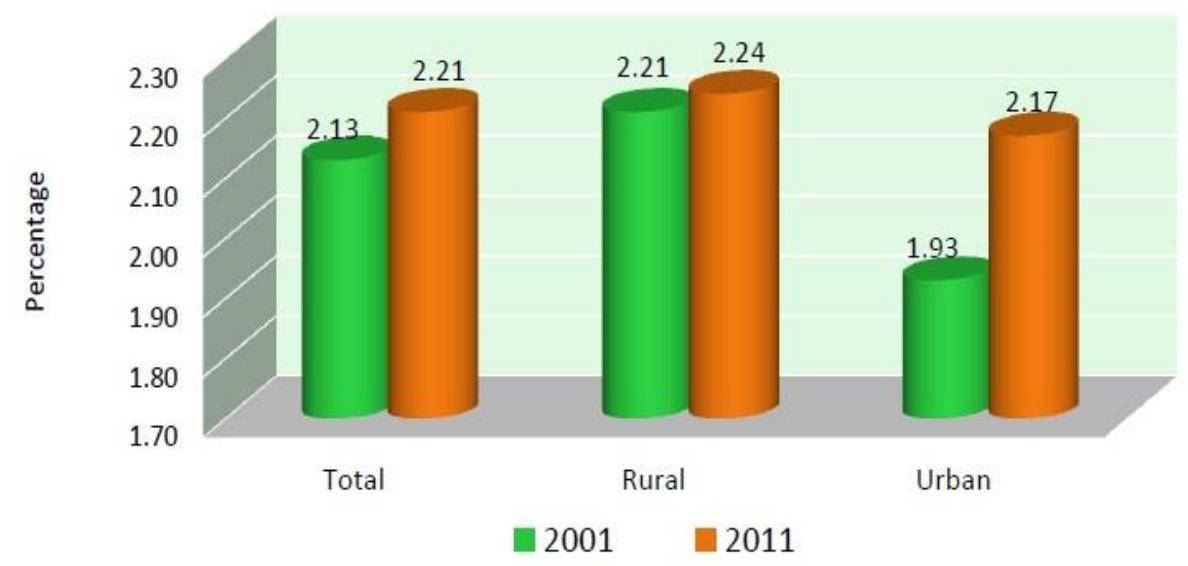

Figure 5 Disabled Population by Residence

Percentage of disabled persons in India has increased both in rural and urban areas during the last decade.

\section{Percentage Share of Disabled Population by Sex India, 2011}

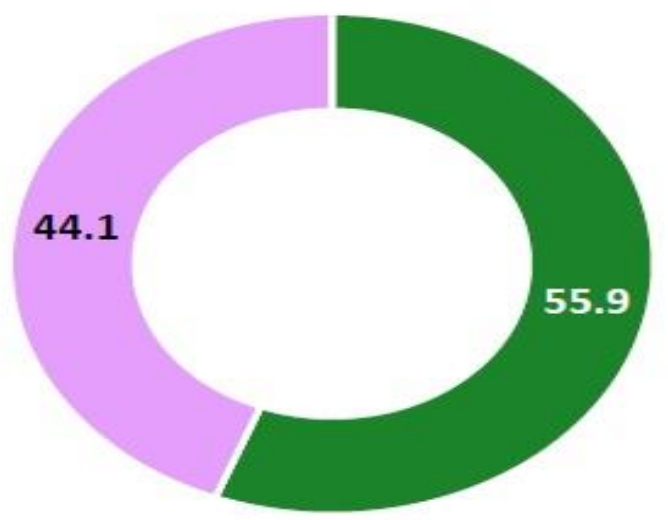

Males

w Females

Figure 6 Disabled Population by Sex 


\section{STEERING MECHANISM}

- Basically the steering in the tricycle is achieved by the rotation of the front wheel about the axis of the column on which the wheel axle is mounted.

- Thus to achieve steering, our main target would be to obtain the rotational movement of the wheel about the column axis using various methods.

\subsection{Ideas that we came across}

Considering our primary working design to be DELTA, the various methods by which the objective of foot steering can be achieved are:

- Foot operated Hydraulic mechanism

- Foot linkage

- Worm and Worm Wheel (Electrical)

\subsection{Method used in our Design - Worm and Worm Wheel Mechanism}

- A worm is provided rotation using ELECTRIC MOTOR, which in turn rotates the worm wheel meshing with it.

- The electric motor is actuated using foot operated DPDT type switching mechanism, so that one position of switch would cause rotation of the motor in one direction, while the other would position would cause it to rotate in other direction.

- The worm wheel is mounted rigidly on the column of the front wheel such that axis of column and worm wheel coincide.

- Desired steering motion is obtained due to rotation of the column.

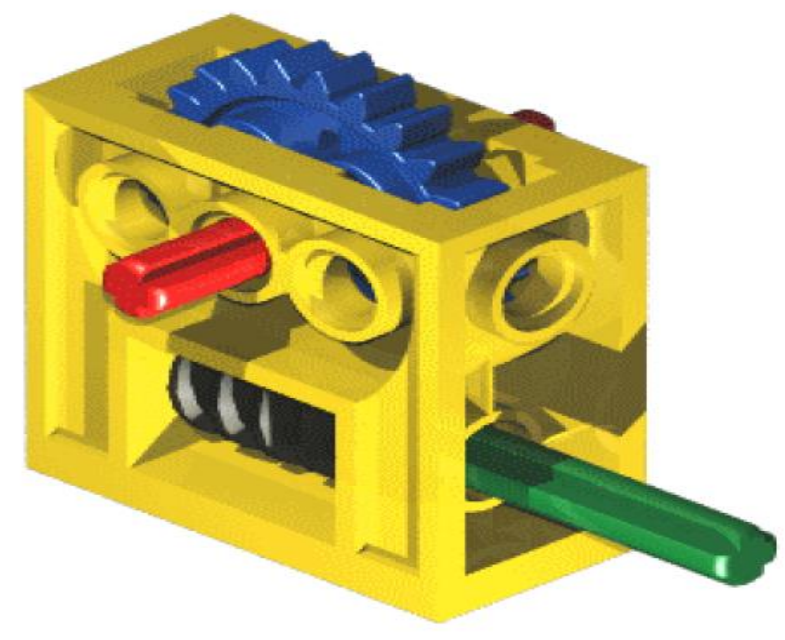

Figure 7 Worm and Worm Wheel

\section{SOFTWARE PTC CREO 2.0}

Creo is a family or suite of design software supporting product design for discrete manufacturers and is developed by PTC.

The suite consists of apps, each delivering a distinct set of capabilities for a user role within product development.

Creo runs on Microsoft Windows and provides apps for 3D CAD parametric feature solid modeling, 3D direct modeling, 2D orthographic views, Finite Element Analysis and simulation, schematic design, technical illustrations, and viewing and visualization. 


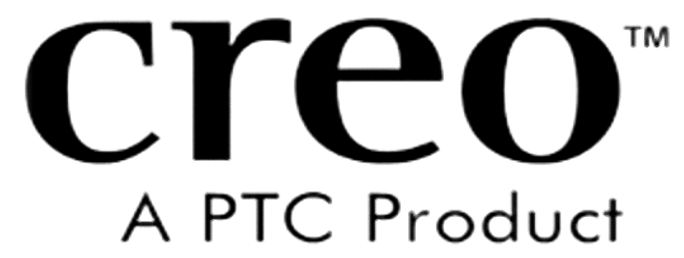

Figure 8 PTC Creo

\subsection{Creo Design}

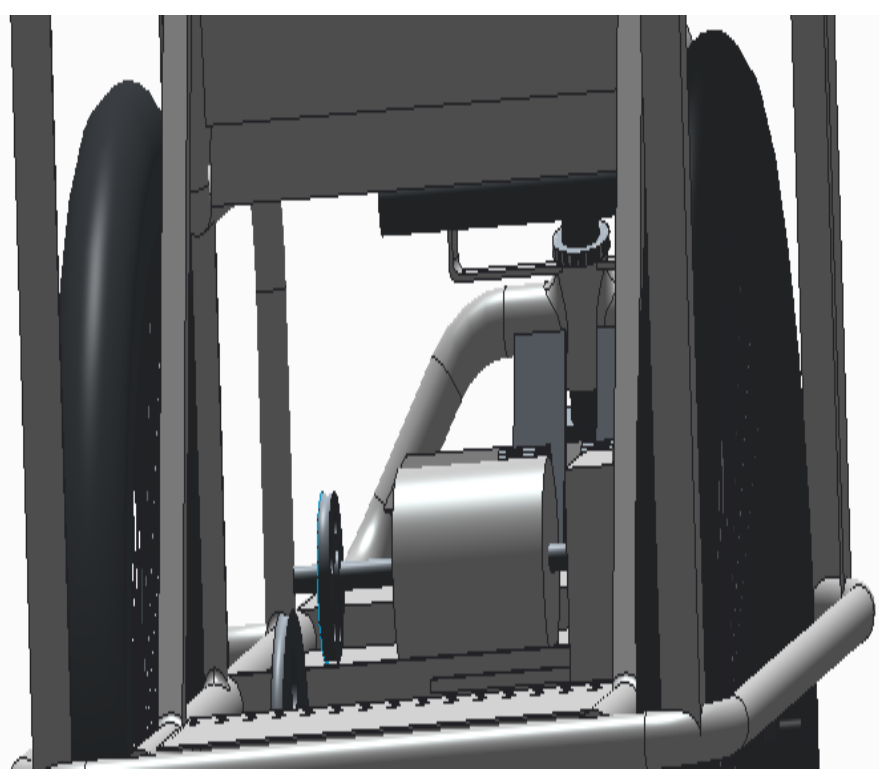

Figure 9 View of Drive

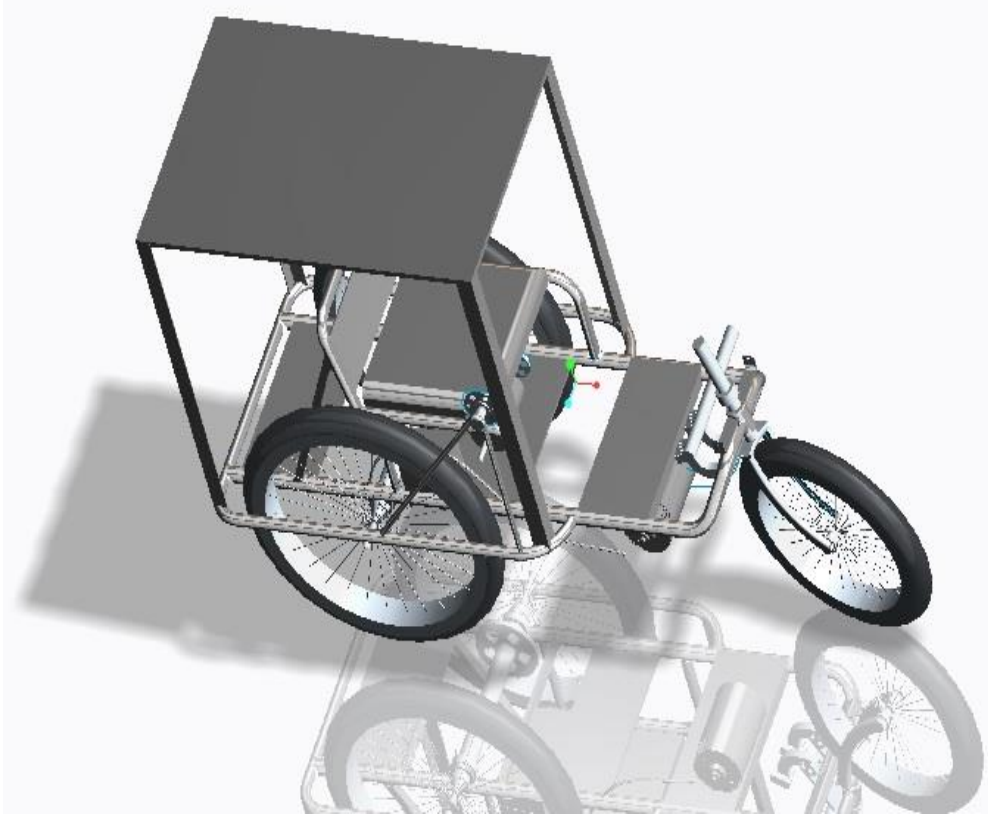

Figure 10 3D View 


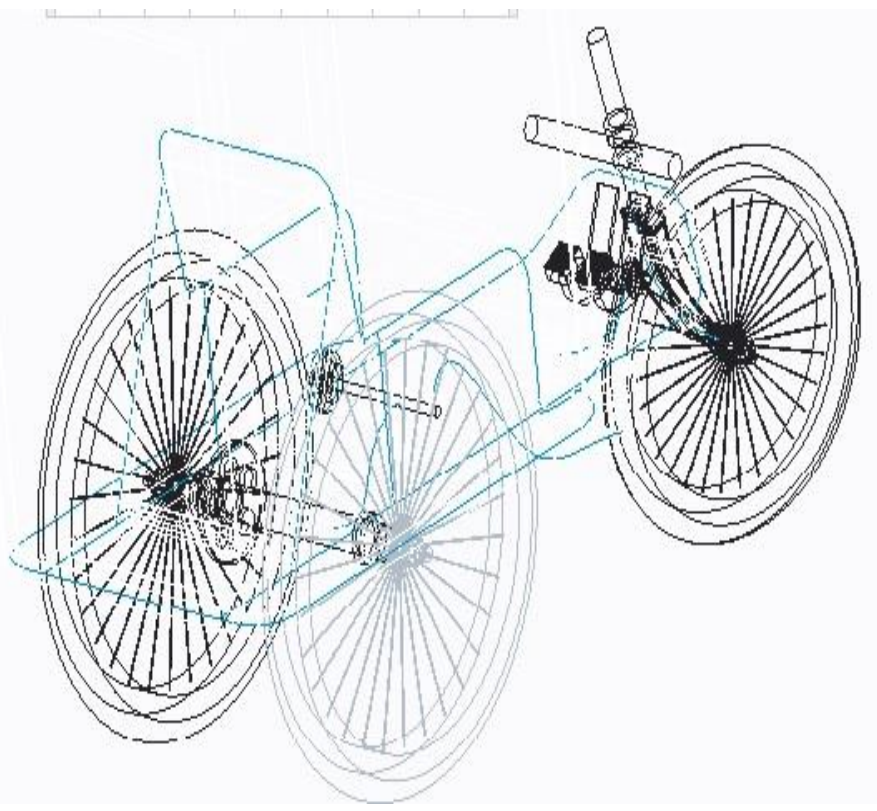

Figure 11 Wireframe View

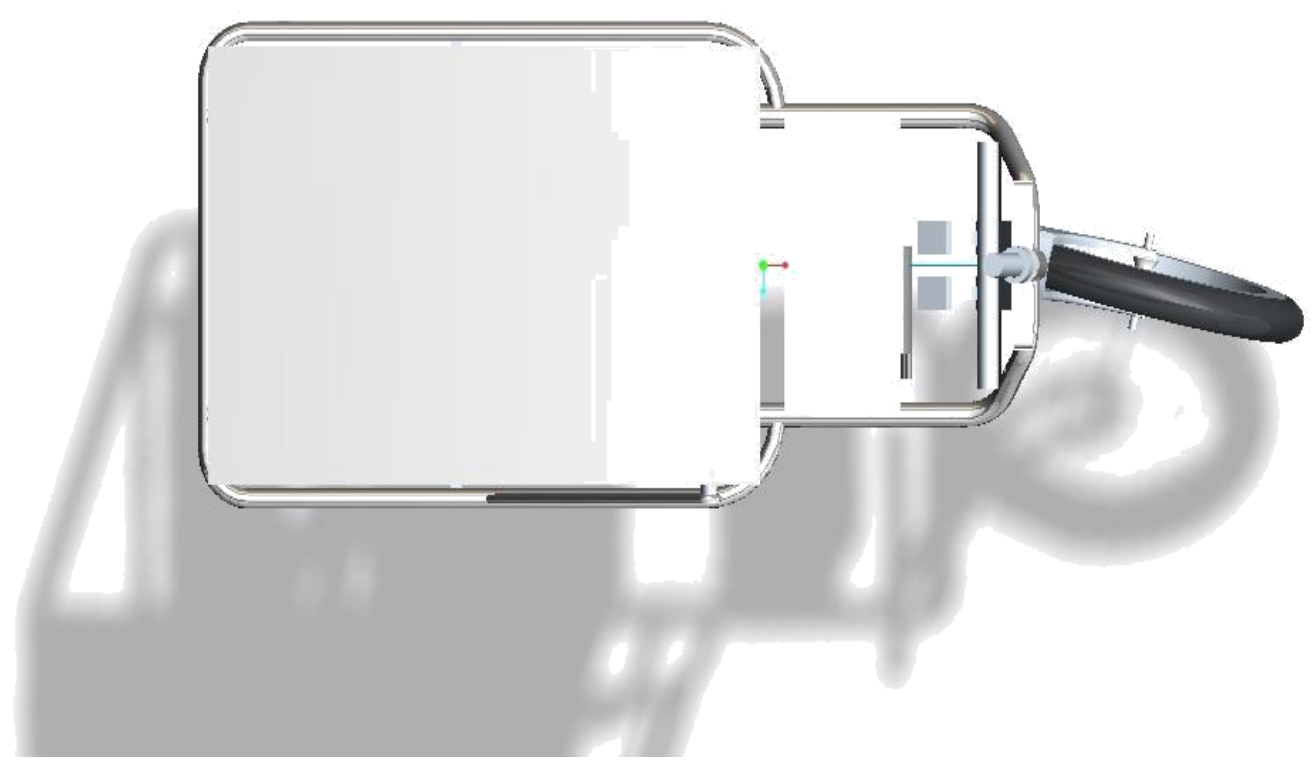

Figure 12 Top View

\section{DESIGN OF THE TRICYCLE}

\subsection{Dimension \& Specifications}

- Overall Length : $1815 \mathrm{~mm}$

- Overall Width : $750 \mathrm{~mm}$

- Weight : $26 \mathrm{~kg}$

\subsection{Features}

- Main Frame: Use of special quality Cold Drawn Bright Annealed tubes of diameter 25.4 x 1.25 $\mathrm{mm}$ wall thickness conforming to IS: 2039 makes the main frame sturdy to withstand stresses caused by rough terrain. Neatly welded joints add further to the strength of main frame. 
- Seat and Back Rest: Seat and Back Rest made from Cold Rolled Annealed Mild Steel Sheet Provides desired sturdiness to the main frame and stability to the user.

- Driving Mechanism: Driven by electric motor using suitable gear arrangement using chain sprockets mounted on the rear axle. This mechanism ensures low driving effort as required by the disabled.

- Steering Mechanism: Two types of steering mechanisms are incorporated. One is the conventional steering handle and other is the worm drive mechanism actuated using motor mounted on the front.

- Rear Container: A specially designed container made from G.I. Sheet is provided at the back to carry necessary tools and belongings.

- Foot Rest: Made from cold rolled annealed M.S Sheet.

- Facility for Selection of Right/Left Hand Drive: Both the options are available. The user can choose Right Hand Drive or Left Hand Drive to suit his/her convenience.

- Finish: Self drying paints impart excellent overall finish.

- Quality Control: ALIMCO observes strict quality control measures at every stage of production and assembly of Tricycle to ensure the reliable product to every needy handicapped.

- Repair \& Maintenance: Requires only routine maintenance. Use of standard Bicycle components ensures easy repair and replacement of parts in the local markets.

\section{SPECIFICATIONS OF COMPONENTS}

- Worm Drive for steering

- Wiper Motor for steering

- BLDC Hub motor for drive

- VRLA Batteries

- Controller for motors

- Voltage Convertor

- Wire Harness

- SPDT Switch

- Electric Accelerator

\subsection{Worm Drive for Steering}

- A worm drive is a gear arrangement in which a worm (which is a gear in the form of a screw) meshes with a worm gear (which is similar in appearance to a spur gear).

- The two elements are also called the worm screw and worm wheel.

- The terminology is often confused by imprecise use of the term worm gear to refer to the worm, the worm gear, or the worm drive as a unit.

- Like other gear arrangements, a worm drive can reduce rotational speed or allow higher torque to be transmitted.

- The image shows a section of a gear box with a worm gear being driven by a worm. 


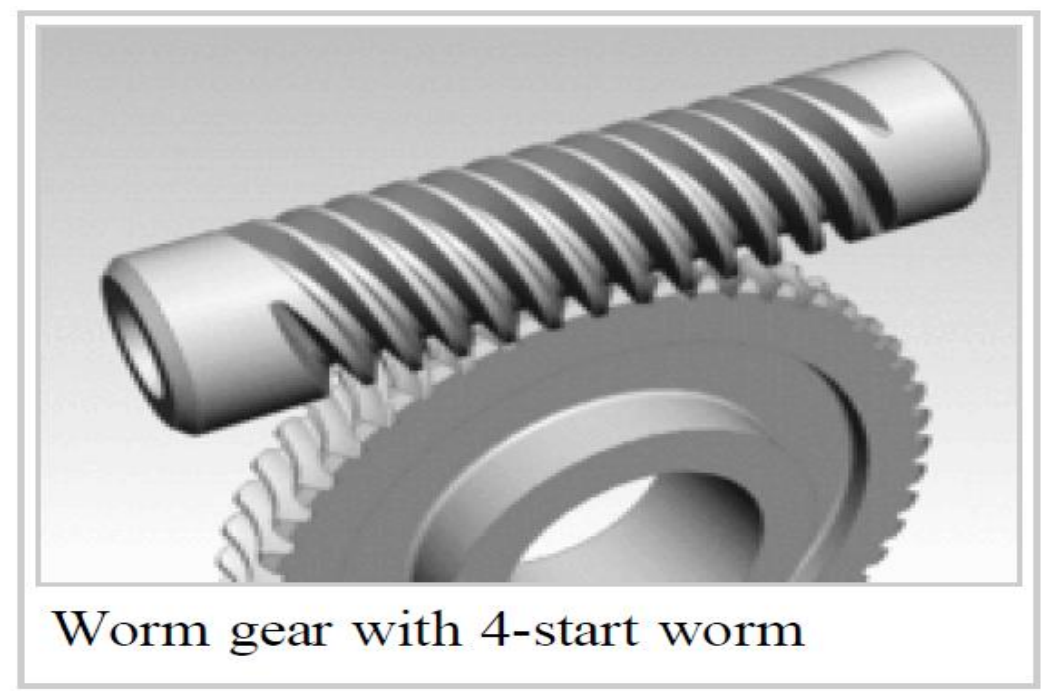

Figure 13 Worm Gear

\subsubsection{Explanation}

- A gearbox designed using a worm and worm wheel will be considerably smaller than one made from plain spur gears and has its drive axes at $90^{\circ}$ to each other.

- With a single start worm, for each $360^{\circ}$ turn of the worm, the worm gear advances only one tooth of the gear.

- Therefore, regardless of the worms size (sensible engineering limits notwithstanding); the gear ratio is the "size of the worm gear to $1 "$.

- Given a single start worm, a 20 tooth worm gear will reduce the speed by the ratio of 20:1.

- With spur gears, a gear of 12 teeth (the smallest size permissible, if designed to good engineering practices) would have to be matched with a 240 tooth gear to achieve the same ratio of 20:1.

- Therefore, if the diametrical pitch (DP) of each gear was the same, then, in terms of the physical size of the 240 tooth gear to that of the 20 tooth gear, the worm arrangement is considerably smaller in volume.

\subsubsection{Direction of Transmission}

- Unlike with ordinary gear trains, the direction of transmission (input shaft vs. output shaft) is not reversible when using large reduction ratios, due to the greater friction involved between the worm and worm wheel, when usually a single start (one spiral) worm is used. This can be an advantage when it is desired to eliminate any possibility of the output driving the input.

- If a multi start worm (multiple spirals) is used then the ratio reduces accordingly and the braking effect of a worm and worm gear may need to be discounted as the gear may be able to drive the worm.

- Worm gear configurations in which the gear cannot drive the worm are said to be self locking.

- Whether a worm and gear will be self locking depends on the lead angle, the pressure angle, and the coefficient of friction; However, it is approximately correct to say that a worm and gear will be self locking if the tangent of the lead angle is less than the coefficient of friction. 


\subsubsection{Applications}

- In early 20th century automobiles prior to the introduction of power steering, the effect of a flat or blowout on one of the front wheels will tend to pull the steering mechanism toward the side with the flat tire. The employment of a worm screw reduced this effect.

- Further development of the worm drive employs recirculating ball bearings to reduce frictional forces, allowing some of the steering force to be felt in the wheel as an aid to vehicle control and greatly reducing wear, which leads to difficulties in steering precisely.

- Worm drives are a compact means of substantially decreasing speed and increasing torque. Small electric motors are generally high speed and low torque; The addition of a worm drive increases the range of applications that it may be suitable for, especially when the worm drive's compactness is considered.

- Worm drives are used in presses, rolling mills, conveying engineering, mining industry machines, on rudders, and worm drive saws. In addition, milling heads and rotary tables are positioned using high precision duplex worm drives with adjustable backlash.

\subsection{Wiper Motor for Steering}

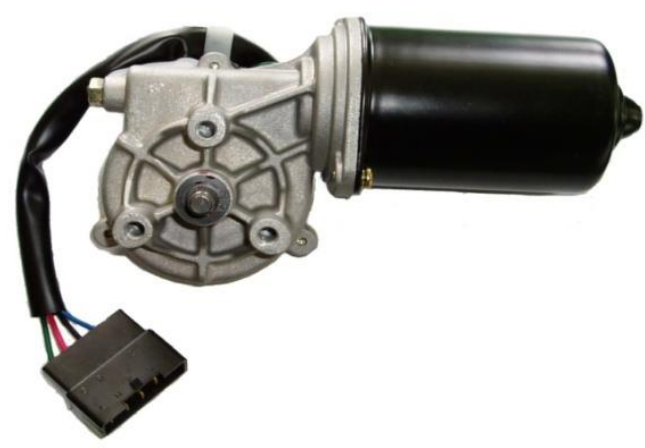

Figure 14 Wiper Motor

- It takes a lot of force to accelerate the wiper blades back and forth across the windshield so quickly. In order to generate this type of force, a worm gear is used on the output of a small electric motor.

- The worm gear reduction can multiply the torque of the motor by about 50 times, while slowing the output speed of the electric motor by 50 times as well.

\subsection{BLDC hub Motor for Drive}

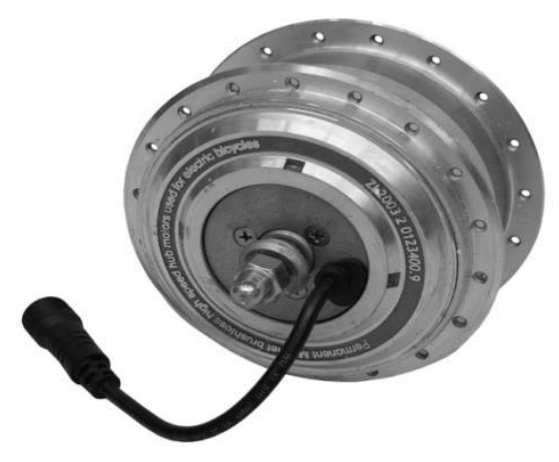

Figure 15 BLDC Motor 
- Hub motor electromagnetic fields are supplied to the stationary windings of the motor. The outer part of the motor follows, or tries to follow, those fields, turning the attached wheel. In a brushed motor, energy is transferred by brushes contacting the rotating shaft of the motor.

- Energy is transferred in a brushless motor electronically, eliminating physical contact between stationary and moving parts.

- Although brushless motor technology is more expensive, most are more efficient and longerlasting than brushed motor systems.

- Electric motors have their greatest torque at start up, making them ideal for vehicles as they need the most torque at start up too.

- Their greatest torque occurs as the rotor first begins to turn, which is why electric motors do not require a transmission. A gear-down arrangement may be needed, but unlike in a transmission normally paired with a combustion engine, no shifting is needed for electric motors.

\subsection{VRLA Battery}

- A VRLA battery (valve regulated lead acid battery), more commonly known as a sealed battery or maintenance free battery, is a type of lead acid rechargeable battery.

- Due to their construction, they can be mounted in any orientation, and do not require constant maintenance.

- They are widely used in large portable electrical devices, off grid power systems and similar roles, where large amounts of storage are needed at a lower cost than other low maintenance technologies like lithium ion.

- There are two primary types of VRLA batteries, gel cells and AGM. Gel cells add silica dust to the electrolyte, forming a thick puttylike gel. These are sometimes referred to as "silicone batteries". AGM (absorbed glass mat) batteries feature fiberglass mesh between the battery plates.

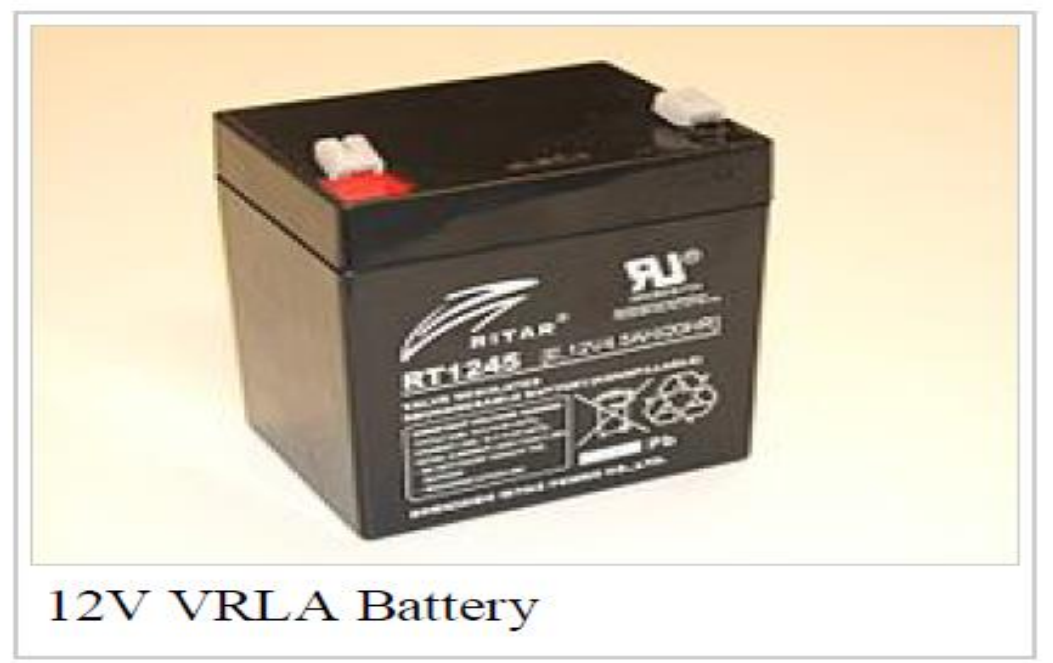

Figure 16 VRLA Battery

\subsubsection{Calculation of Battery Capacity}

- The Ampere-Hour requirement is decided based on the starting current requirement.

- The Battery used should have battery capacity greater than starting current of motor. 


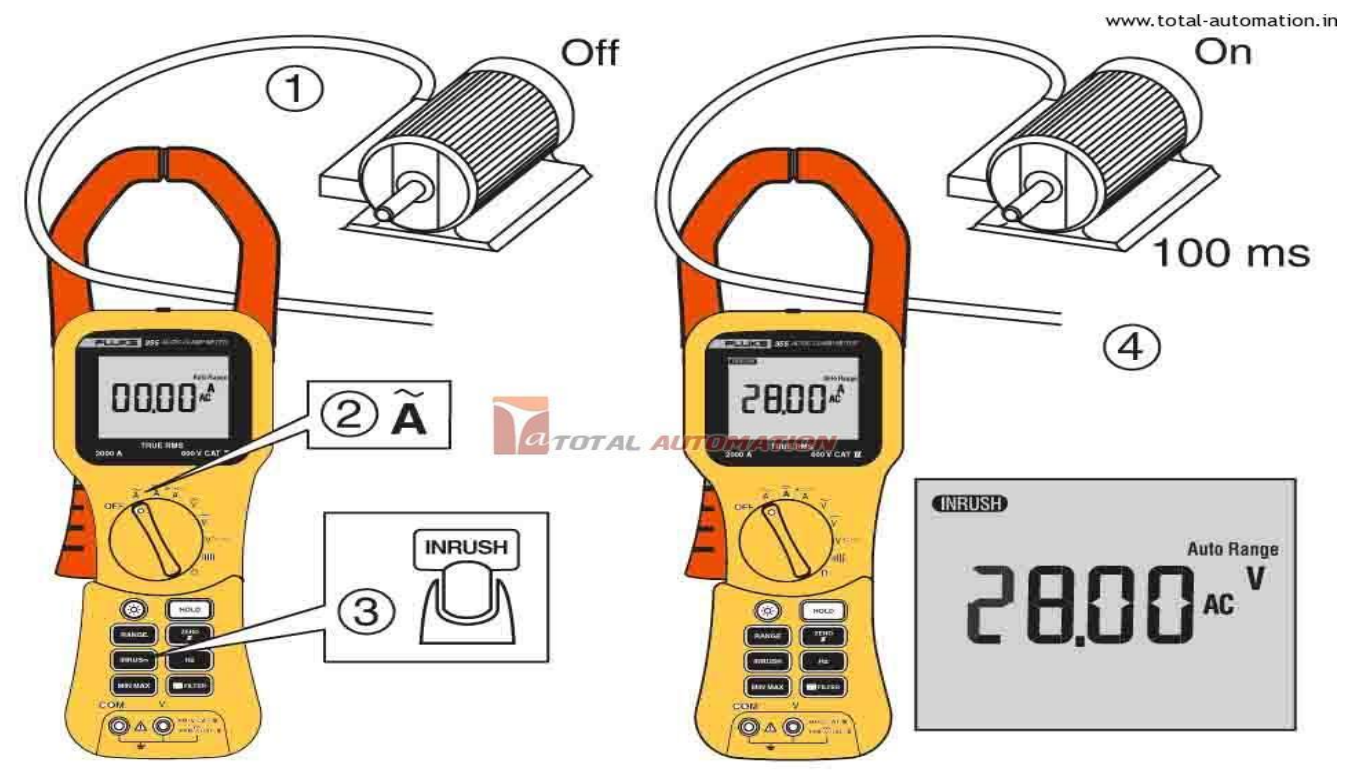

Figure 17 Clamp Meter

\subsection{Motor Controller}

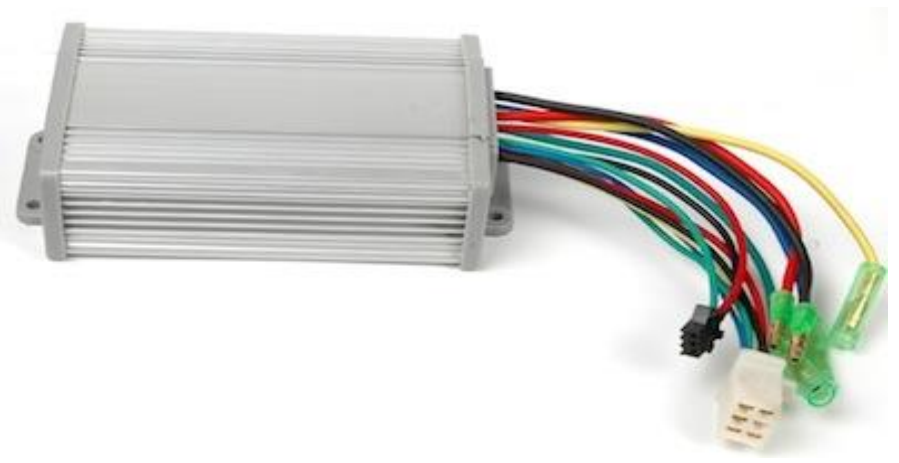

Figure 18 Motor Controller

- A motor controller is a device or group of devices that serves to govern in some predetermined manner the performance of an electric motor.

- A motor controller might include a manual or automatic means for starting and stopping the motor, selecting forward or reverse rotation, selecting and regulating the speed, regulating or limiting the torque, and protecting against overloads and faults.

- The simplest case is a switch to connect a motor to a power source, such as in small appliances or power tools. The switch may be manually operated or may be a relay or contactor connected to some form of sensor to automatically start and stop the motor.

The switch may have several positions to select different connections of the motor. This may allow reduced-voltage starting of the motor, reversing control or selection of multiple speeds.

- More complex motor controllers may be used to accurately control the speed and torque of the connected motor (or motors) and may be part of closed loop control systems for precise positioning of a driven machine. 


\subsection{Voltage Convertor}

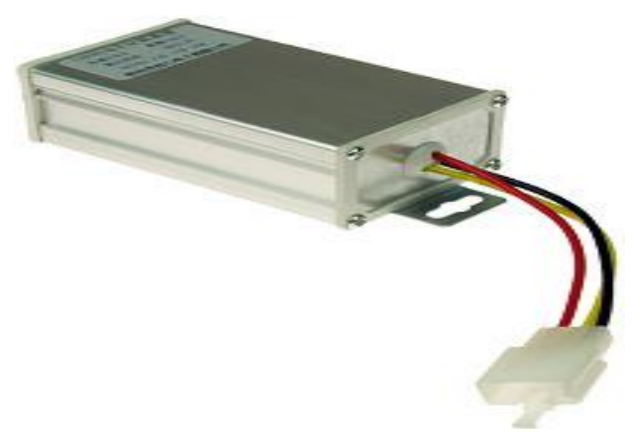

Figure 19 Voltage Convertor

- Voltage converters can be used in vehicles with $12 \mathrm{~V}$ DC outlets. A simple voltage dropper can be used to reduce the voltage for low-power devices like Horn, Head Light, Tail Light, Side Light, etc.

- If more than $12 \mathrm{~V}$ is required, or for high-powered devices, a switched-mode power supply is used. The output will usually be DC in the range $1.5-24 \mathrm{~V}$.

\subsection{Wire Harness}

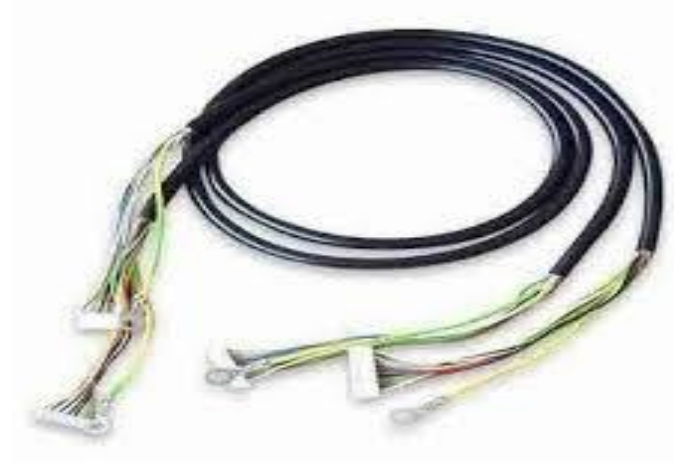

Figure 20 Wire Harness

For electrical connection between various components.

\subsection{SPDT Switch}

Another common switch type is the SPDT. SPDTs have three terminals: one common pin and two pins which vie for connection to the common.

SPDTs are great for selecting between two power sources, swapping input or whatever it is you do with two circuits trying to go one place. Most simple slide switches are of the SPDT variety. SPDT switches should usually have three terminals. (Side note: in a pinch an SPDT can actually be made into an SPST by just leaving one of the switch throws unconnected). 


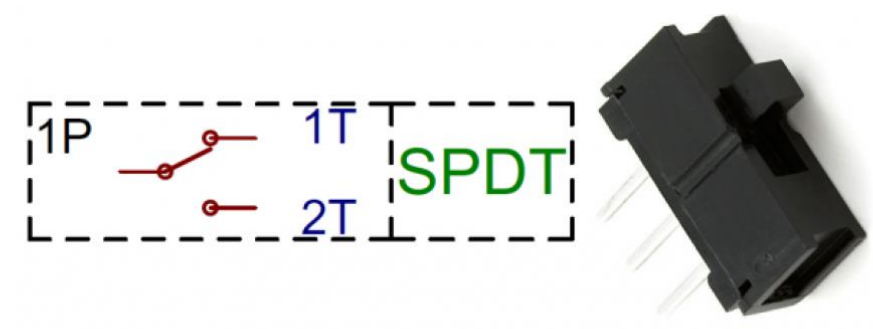

An SPDT switch circuit symbol, and an SPDT slide switch.

Figure 21 SPDT Switch

\subsection{Electric Accelerator}
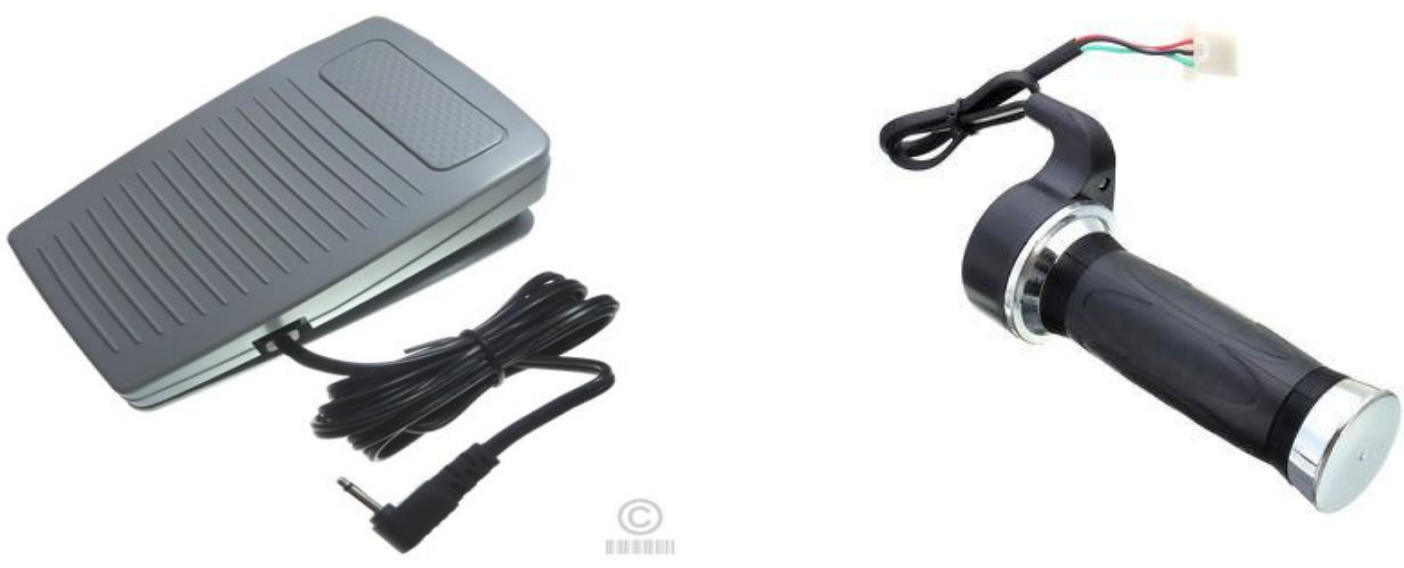

Figure 22 Electric Accelerator

Device used for accelerating the tricycle by help of foot.

\section{MATERIALS USED FOR WORM}

Worm gear sets are usually used to reduce speed and increase torque. Since the worm drive undergoes more contact stress cycles than the worm gear, the worm drive is usually of a stronger material.

- Cast iron provides durability and ease of manufacture.

- Alloy steel provides superior durability and corrosion resistance. Minerals may be added to the alloy to further harden the gear.

- Cast steel provides easier fabrication, strong working loads and vibration resistance. Carbon steels are inexpensive and strong, but are susceptible to corrosion.

- Aluminium is used when low gear inertia with some resiliency is required. Brass is inexpensive, easy to mould and corrosion resistant.

- Copper is easily shaped, conductive and corrosion resistant. The gear's strength would increase if bronzed.

- Plastic is inexpensive, corrosion resistant, quiet operationally and can overcome missing teeth or misalignment. Plastic is less robust than metal and is vulnerable to temperature changes and chemical corrosion. 


\subsection{Prototype Overview}

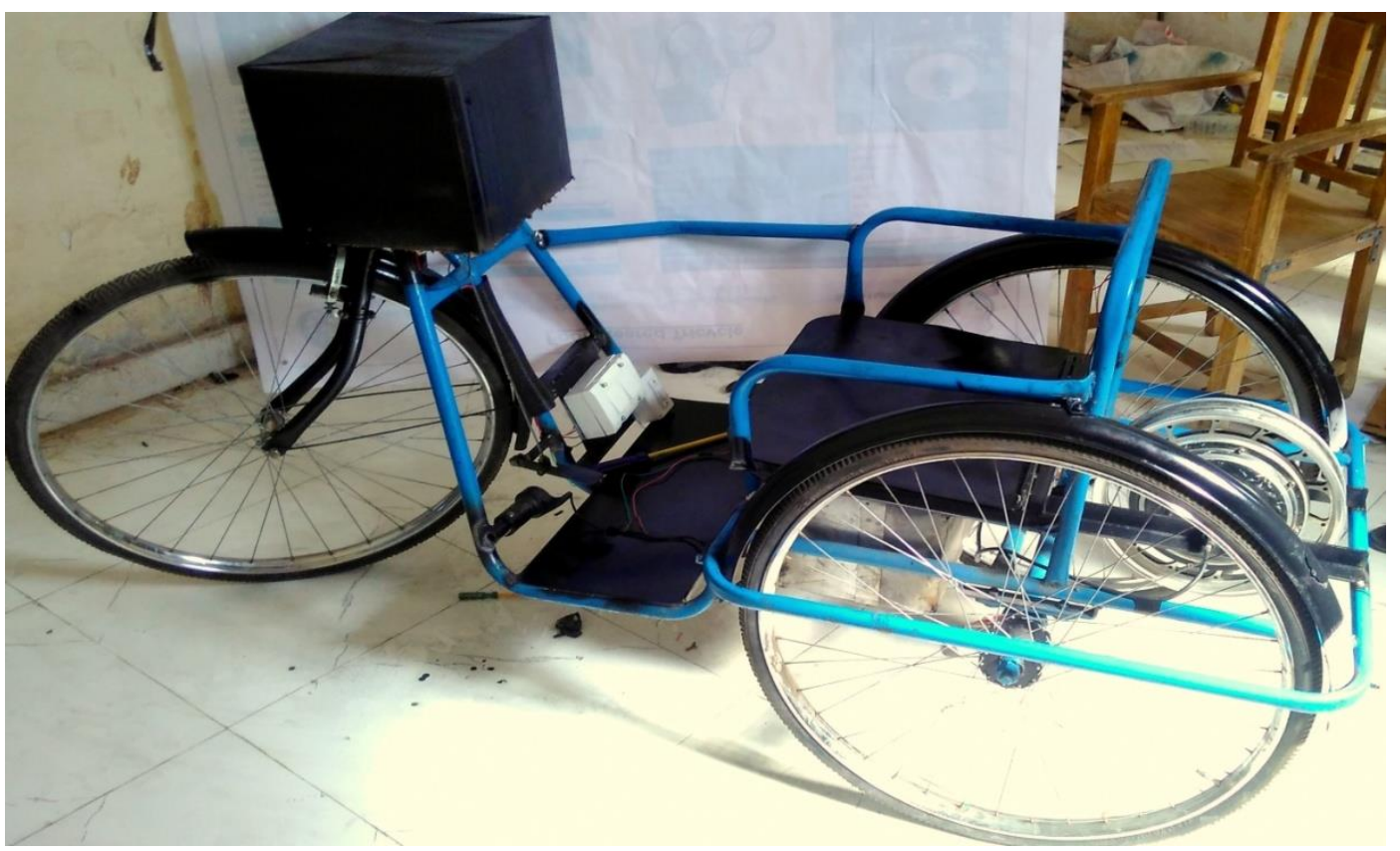

Figure 23 Overview

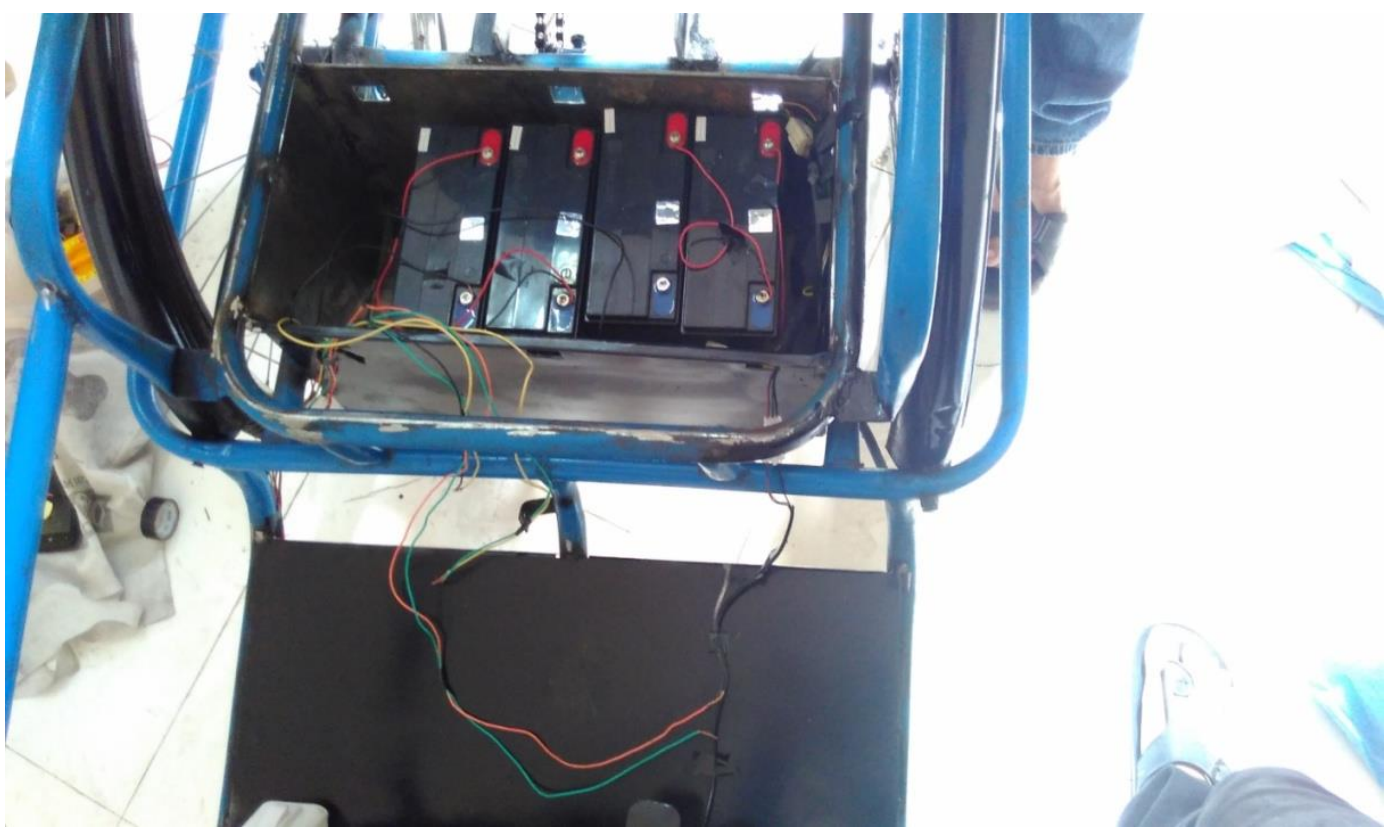

Figure 24 Storage for Batteries 
Samip Mehta, Deven Godhani, Nauman Vadnagarwala, Chirag Shivdas

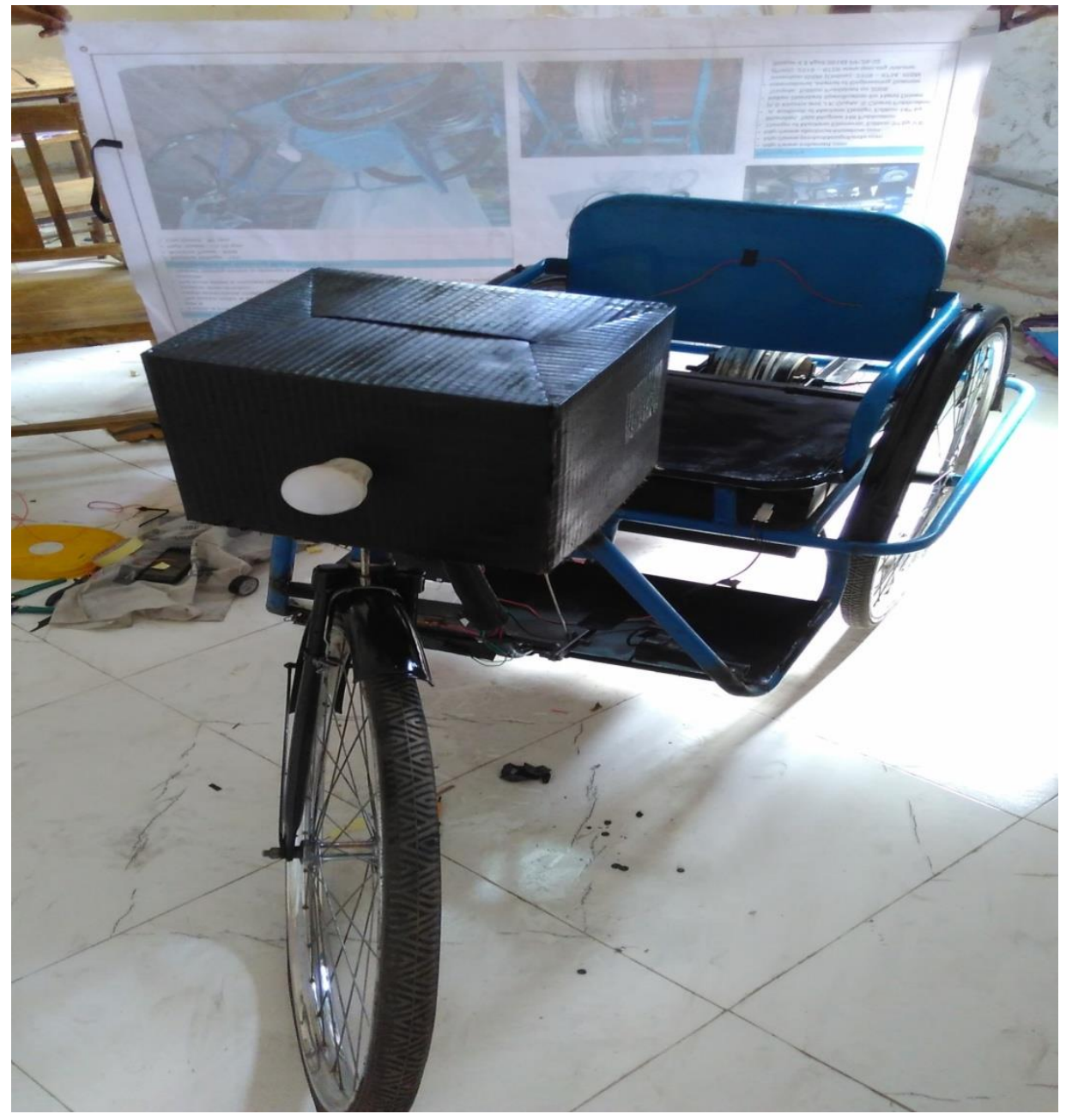

Figure 25 Front View

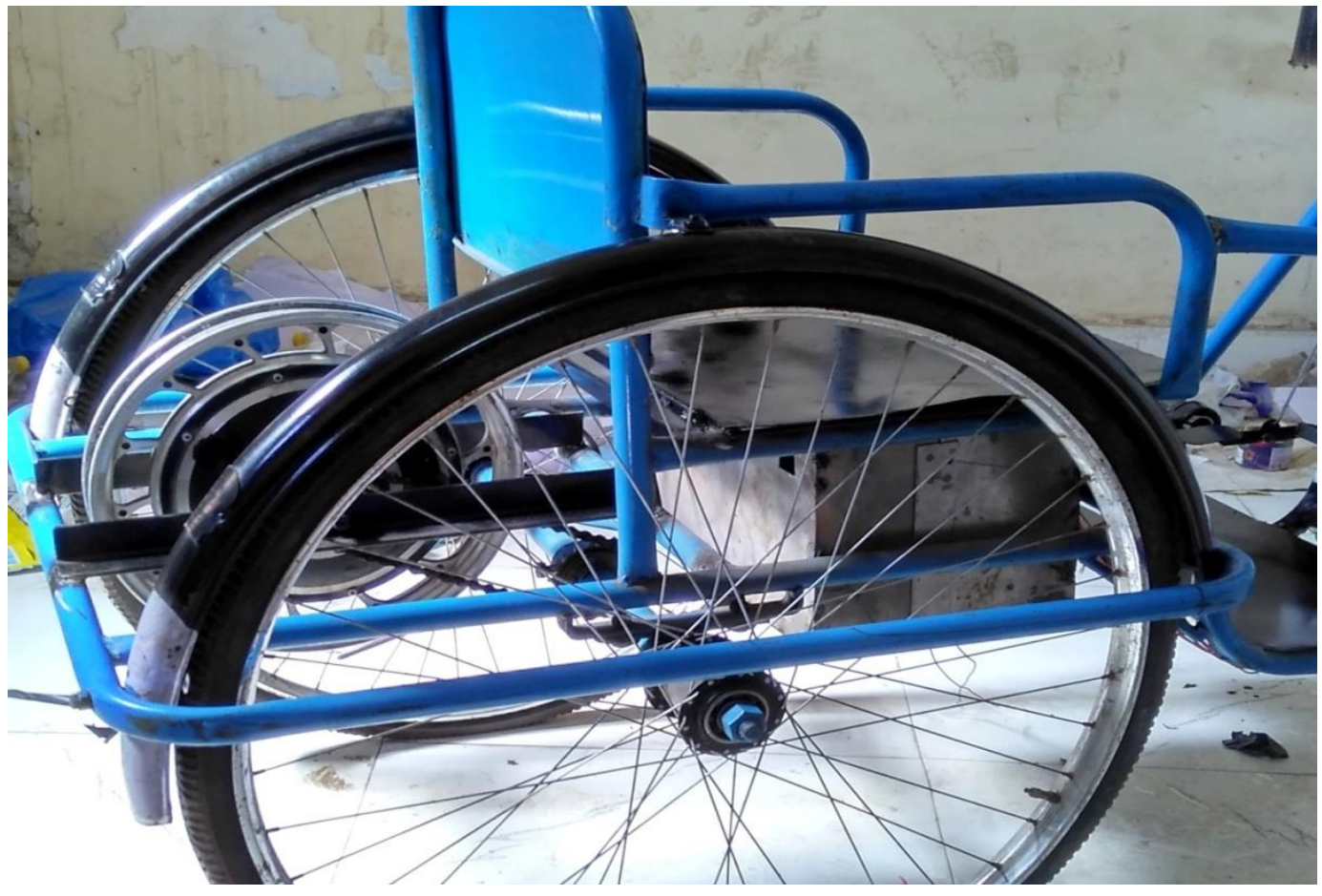

Figure 26 Electric Hub Motor Mouting 


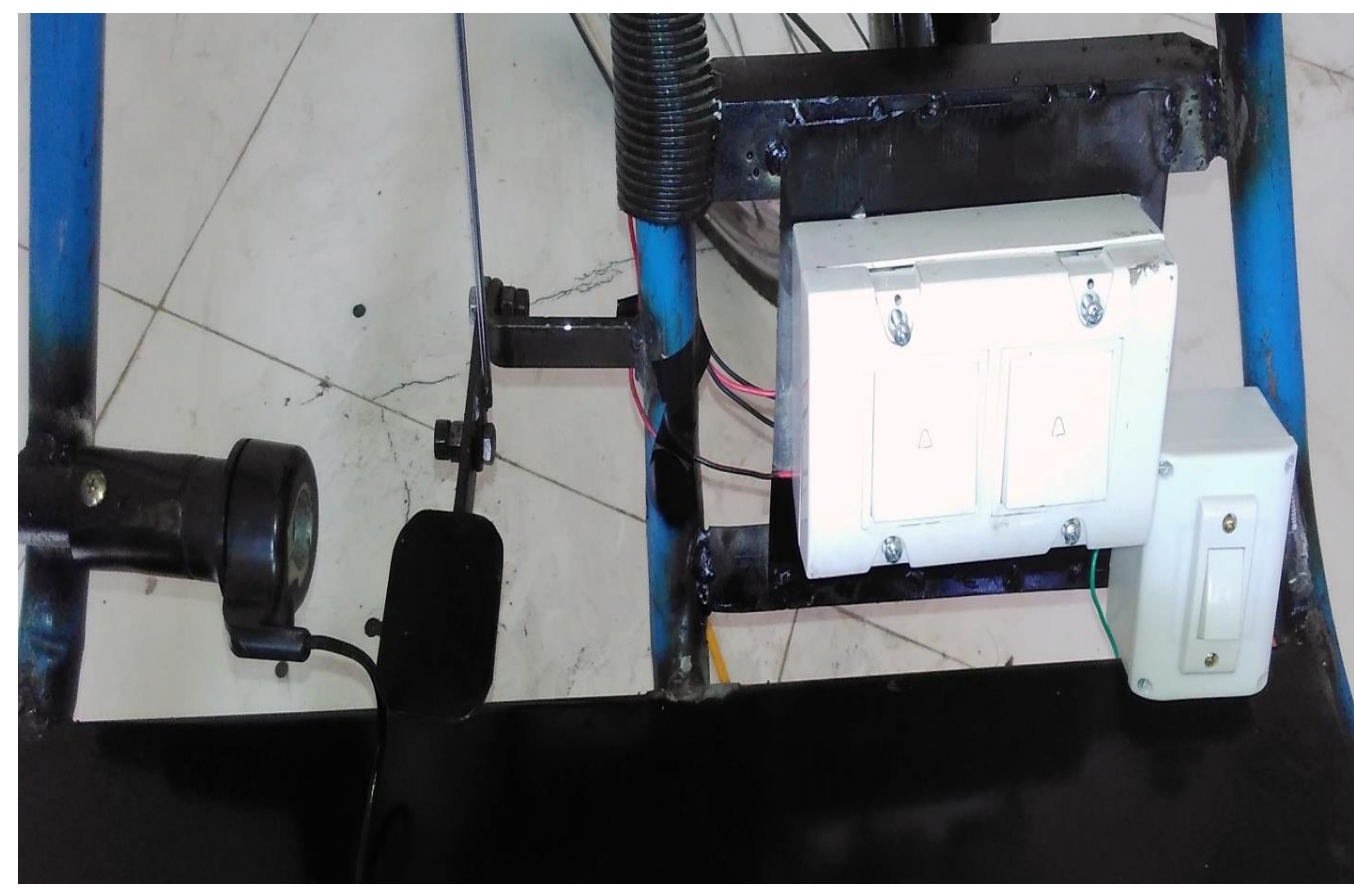

Figure 27 Accelerator, Brake Pedal, Switches for Steering

\section{REFERENCES}

[1] www.indiamart.com

[2] 'Design of Machine Elements' Edition 3rd by V.B Bhandari, Tata-Mcgraw Hill Publication

[3] 'A textbook of Machine Design' Edition 14th by R.S Khurmi and J.K Gupta, S Chand Publication

[4] 'Design Data Book' by PSG

[5] Census 2011 by Gov. of India

[6] Satish Kumar Dwivedi, Deepak Kumar Yadav, Ashutosh Mishra, Madhusudan Jaiswal, Shrikant Singh, and Sujeet Kumar, "Design and Fabrication of a Motorized Tricycle for Physically Challenged Persons", International Journal of Engineering Science Invention (www.ijesi.org), Vol. 3, Issue. 4, April 2014, PP. 29-32

[7] Adedipe Oyewole, Bala Katsina Christopher and Sadiq Ibrahim Ogu, "Design and Construction of a Motorized Tricycle for Physically Challenged Persons", AU JOURNAL OF TECHNOLOGY, Vol.13, Issue. 1, 2009, pp. 61-63

[8] www.electrical-knowhow.com

[9] www.instructables.com

[10] Indian Standard Specification for Hand Driven Tricycle, Edition Published on 2008

[11] Nishad Kumbhojkar, Kunal Mohite, Anand Kulkarni and Sanket Patil, Design and Implementation of Kinetic Energy Recovery System (KERS) in Bicycle. International Journal of Mechanical Engineering and Technology, 6 (4), 2015, pp. 101-108.

[12] Rajnish Katarne and Dr. Jayant Negi, Determination of Importance of Criteria: Analytic Hierarchy Process (AHP) in Technological Evolution of Automobile Steering. International Journal of Design and Manufacturing Technology (IJDMT), 4 (1), 2013, pp. 10-18. 